\title{
Thermal behavior and physicochemical studies of phase transitions before the decomposition in the Selenate Tellurate protonic conductor material.
}

\author{
I. GOUTI ${ }^{1}$, H. LITAIEM ${ }^{1}$ and S. GARCIA- GRANDA ${ }^{2}$
}

1 Laboratoire de Chimie Inorganique, Faculté des Sciences de Sfax, Université de Sfax, B.P1171 Sfax 3000, Tunisie.

2 Laboratoire de Chimie Physique et Analytique, Faculté de Chimie, Vniversité d'Oviedo, Oviedo 33006, Espagne.

\section{Highlights:}

- Thermal analysis shows two phase transitions at 320 and $490 \mathrm{~K}$ before the decomposition.

- The high temperature structural study and the deconvolutions of Raman spectra prove that the transition at $320 \mathrm{~K}$ is a structural phase transition.

- The dielectric study shows that this material has a ionic protonic conduction phase transition in the range of $\mathrm{T}=490 \mathrm{~K}$.

\begin{abstract}
:
Thermal analysis confirmed the presence of the phase transition at $\mathrm{T}=320 \mathrm{~K}$ in the $\mathrm{Cs}_{2} \mathrm{SeO}_{4} \cdot \mathrm{H}_{6} \mathrm{TeO}_{6}(\mathrm{CsSeTe})$ material. The structural study carried out at $\mathrm{T}=360 \mathrm{~K}$ shows that this compound passes from the monoclinic system with the space group $\mathrm{P} 21 / \mathrm{c}$ at room temperature, to the trigonal system with the space group $\mathrm{R} \overline{3} \mathrm{~m}$. At room temperature, the anionic groups are well ordered and stable, whereas after the transition at $\mathrm{T}=320 \mathrm{~K}$, the selenate groups change their orientation and the tellurate polyhedra change their positions.
\end{abstract}


The high temperature vibrational studies, carried out in a temperature range of 289 to $353 \mathrm{~K}$, confirm the presence and nature of the transition detected by thermal analysis. The conductivity evolution versus temperature shows the presence of an ionic- protonic conduction phase transition at $\mathrm{T}=490 \mathrm{~K}$.

Keywords: Differential Scanning Calorimetry (DSC); Crystal structure; IR; Raman; conductivity.

\section{Introduction:}

Recently, researchers are interested in the preparation of inorganic materials thanks to their interesting architectures which are related to the structural changes under the effect of various factors such as temperature. In fact, telluric acid has the specificity of forming several stable addition compounds with some varieties of inorganic materials like selenate, sulfate and hydrogeno - arsenate. In fact, adduct compounds present a structural order- disorder phase transition [1], they associated physical properties like ionic- protonic superconductivity, ferroelectricity and dielectric relaxation, used in multilayer capacitors, microelectronic components and material of energy storage [2 - 4].

In this respect, we report in this paper the results of the investigation pertaining to the $\mathrm{Cs}_{2} \mathrm{SeO}_{4} \cdot \mathrm{Te}(\mathrm{OH})_{6}(\mathrm{CsSeTe})$ material, $\mathrm{X}$-ray diffraction and Raman analysis have been undertaken to examine the behavior of the anionic groups and the nature of the phase transition detected by thermal study at $\mathrm{T}=320 \mathrm{~K}$. 
Furthermore, the dielectric proprieties of the (CsSeTe) compound have been reported, they show the presence of the ionic- protonic conduction phase transition before the decomposition in this material.

\section{Experimental phases:}

\section{1-Chemical preparation:}

Colorless and transparent single Crystals of the cesium selenate tellurate (CsSeTe) were prepared by slow evaporation at room temperature from a mixtre in stoichiometric quantities of telluric acid $\mathrm{H}_{6} \mathrm{TeO}_{6}$, cesium carbonate $\mathrm{Cs}_{2} \mathrm{CO}_{3}$ and selenic acid $\mathrm{H}_{2} \mathrm{SeO}_{4}$ with the following reaction:

The formula of this material was determined by chemical analysis and confirmed by structural refinement at room temperature.

$$
\mathrm{H}_{6} \mathrm{TeO}_{6}+\mathrm{Cs}_{2} \mathrm{CO}_{3}+\mathrm{H}_{2} \mathrm{SeO}_{4} \stackrel{\mathrm{H}_{2} \mathrm{O}}{\longrightarrow} \mathrm{Cs}_{2} \mathrm{SeO}_{4} \cdot \mathrm{Te}(\mathrm{OH})_{6}+\mathrm{H}_{2} \mathrm{O}+\stackrel{\mathrm{CO}_{2}}{\stackrel{7}{\longrightarrow}}
$$

\section{2- Diffraction data collection and refinement:}

The diffraction data from a selected single crystal from the compound, at $\mathrm{T}=360 \mathrm{~K}$, were collected on A Xcalibur Gemini S Diffractometer equipped with Mo K $\alpha$ radiation $(\mathrm{K}=0,7107 \AA)$. The data were processed with Oxford diffraction Crys Alis CCD and Crys Alis RED [5]. Software and empirical absorption correction using spherical harmonics were implemented in SCALE3 ABSPACK scaling algorithm. The crystal structure and refinement were carried out using SHELX programs $[6,7]$. 
The (CsSeTe) structure was solved firstly by locating the Te, Cs and Se atoms by Patterson methods and subsequently the $\mathrm{O}$ atoms positions were deduced from Difference Fourier Maps. The final cycle of refinement leads to the factors $\mathrm{R}$ and WR converged respectively to 0.028 and 0.031 .

The structure graphics were created using the DIAMOND Program [8].

\section{3- Thermal behavior measurements:}

A Mettler-Toledo DSC model DSC821 was used for Differential Scanning Calorimetry (DSC) measurements in air atmosphere, at a heating rate of $10 \mathrm{Kmin}^{-}$ 1. $30.02 \mathrm{mg}$ of the samples was thermally treated from 200 to $800 \mathrm{~K}$.

\section{4- Infrared and Raman measurements:}

The infrared absorption spectra of crystalline suspension in $\mathrm{KBr}$ were registered using Jasco - FT-IR -420 spectrophotometer in the frequency range of 400-4000 $\mathrm{cm}^{-1}$. At various temperatures, the Raman spectra of polycrystalline samples sealed in glass tubes were recorded on a Labrama HR 800 instrument using 632.81 $\mathrm{nm}$ radiations from a physics argon ion laser. The spectrum was stored in the frequency range of $50-1200 \mathrm{~cm}^{-1}$.

\section{5- Conductivity measurements:}

The conductivity measurements were performed using a Hewlett- Pakard 4192 A LF automatic bridge. The temperature was measured with a chromel-alumel thermocouple close to the sample and data were collected in air in the temperature range $400-555 \mathrm{~K}$. 


\section{Results and discussion:}

\section{I - Chemical and scanning electron microscope analyses:}

Chemical preparation was carried out to determine tellurium and selenium in the cesuim selenates tellurates obtained. for this purpose, bichromatic and gravimetric methods were used [9-10].

The alkali metals present in this material were determined by titration with sulfuric acid in presence of indicator - methyl orange. The results obtained from the chemical analysis are shown in Table 1.

The chemical purity of the product was tested by analysis of X- ray (EDAX) measurements (Figure 1). The EDAX spectrum of (CsSeTe) reveals the presence of all non- hydrogen atoms: Te, Se, Cs and O. the electron microscopy (SEM) image is shown in (Figure 2).

\section{I - Thermal analysis:}

The Differential Scanning Calorimetry (DSC) analysis of (CsSeTe) material reported in Figure 3 shows three phase transitions at 320, 530 and $726 \mathrm{~K}$, respectively. The calculated values of the transition enthalpy $(\Delta \mathrm{H})$ and entropy $(\Delta \mathrm{S})$ for the first phase transition at $320 \mathrm{~K}$ are $2.65 \mathrm{KJmol}^{-1}$ and $8.28 \mathrm{Jmol}^{-1} \mathrm{~K}^{-1}$, respectively.

The mechanism experimentally observed in transition entropy can be performed in terms of Boltzmann's principe [11]: $\Delta S=R \operatorname{Ln}(\Omega)=R \operatorname{Ln}\left(\mathrm{N}_{1} / \mathrm{N}_{2}\right)$. 
Where $\mathrm{N} 1$ and $\mathrm{N} 2$ are the numbers of distinguishable orientations allowed in the high and low temperature phase respectively [12]. The observed value of entropy $\Delta S$ leads to $\mathrm{N}_{1} / \mathrm{N}_{2}=2.712 \approx 3$, the rapport number of $\mathrm{N}_{1} / \mathrm{N}_{2}$ probably reflects the reorientation and translation of the selenate and tellurate groups and conformational modification of the atoms between different positions, as the entropy value is near 3 . So, the phase transition at $\mathrm{T}=320 \mathrm{~K}$ can be classified as the structural phase transition due to the changing orientation and position of the different groups. The endothermic and intense peak observed at $\mathrm{T}=530 \mathrm{~K}$ accompanied by two shoulders at $490 \mathrm{~K}$ and $545 \mathrm{~K}$, with transition enthalpy and entropy determined are respectively $1257.67 \mathrm{KJmol}^{-1}$ and $237.29 \mathrm{Jmol}^{-1} \mathrm{~K}^{-1}$. We refer to the later studies of addition compounds based on telluric acid [1,13-14], we can say that the transitions at $\mathrm{T}=530,545$ and $726 \mathrm{~K}$ are related to the decomposition of the (CsSeTe) material.

\section{II - Structural Study:}

The $\mathrm{Cs}_{2} \mathrm{SeO}_{4} \cdot \mathrm{Te}(\mathrm{OH})_{6}$ compound is crystallized at $\mathrm{T}=360 \mathrm{~K}$ in the trigonal system $\mathrm{R} \overline{3} \mathrm{~m}$, with the following parameters: $\mathrm{a}=\mathrm{b}=7.5345(8) \AA, \mathrm{c}=8.5545$ (10) $\AA$, $\gamma=$ $120^{\circ}, Z=2$ and $V=420.55(8) \AA^{3}$ Table 2. While at room temperature, it crystallized in the monoclinic system $\mathrm{P} 2{ }_{1} / \mathrm{c}$, we notice the unit cell parameters are approximately similar that the structure realized by Dammak et All [15] : $\mathrm{a}=12.7906(10) \AA, \mathrm{b}=7.4990(4) \AA, \mathrm{c}=12.4031(10) \AA, \beta=111204(9){ }^{\circ}$ and $V=1109.13(14) \AA^{3}$. 
The increase in temperature leads to the transformation of the structure and the unit cell parameters decrease. In fact, it is affecting the cell volume (volume decrease is almost $1 / 2$ of that at room temperature).

On the other hand, a great deformation of the polyhedra is found in this structure. The arrangement of different groups is shown in Figure 4. At high temperature, the structure of CsSeTe material is formed of selenate and tellurate coordination polyhedra, in the presence of the $\mathrm{Cs}^{+}$cations, meanwhile at room temperature the structure is made of regular $\mathrm{TeO}_{6}$ octahedra alterning with regular $\mathrm{SeO}_{4}$ tetrahedra, the $\mathrm{Cs}^{+}$cations are intercalated in bidimensional arrangements between the two types of polyhedra.

At room temperature, the octahedron were regular, the $\mathrm{Te}-\mathrm{O}$ distances vary from 1.899(5) $\AA$ to $1.910(5) \AA$ and the $\mathrm{O}-\mathrm{Te}-\mathrm{O}$ angles are between $87.6(2)^{\circ}$ and 92.4 $(2)^{\mathbf{o}}$ [15].

While at high temperature the polyhedron loses the octahedron coordination to be surrounded by eight oxygen atoms $\left(6 \mathrm{O}_{5}\right.$ and $\left.2 \mathrm{O}_{6}\right)$, where the tellurium atom occupies three adjacent positions. Consequently, the octahedron gets in motion occupying three different positions as shown in Figure 5, according to the result detected by DSC (The observed value of entropy $\Delta \mathrm{S}$ leads to $\mathrm{N}_{1} / \mathrm{N}_{2} \approx 3$ ), all coordinated atoms keeping the coordination of six oxygen atoms. In fact, the oxygen atoms of the tellurium occupy eight positions (six positions of $\mathrm{O}_{5}$ and two positions of $\mathrm{O}_{6}$ ) and the sum of all occupancies is complementary nearly six, the 
Te -O bond length varies from 1.90 (3) $\AA$ to 1.95 (3) $\AA$ and the $\mathrm{O}-\mathrm{Te}-\mathrm{O}$ angles are between $35.6(2)^{\circ}$ and $60.5(2)^{\circ}$.

In this structure at $\mathrm{T}=360 \mathrm{~K}$ the selenium atom coordination polyhedron is surrounded by eighteen oxygen atoms $\left(12 \mathrm{O}_{1}\right.$ and $\left.6 \mathrm{O}_{2}\right)$ Figure 6. Thus, occupying three different positions of the $\mathrm{SeO}_{4}$ tetrahedron, the position of the central atom remains essentially unchanged. Figure 7 shows a tetrahedron in one position of this material. The eighteen oxygen atoms (twelve positions of $\mathrm{O}_{1}$ and six positions of $\mathrm{O}_{2}$ ) occupy eighteen positions and the results of the sum of all occupancies are complementary nearly twelve. Therefore, we can say that the number of tetrahedra positions is three in accordance with the number of distinguishable orientations allowed in the high temperature phase given by the entropy $\Delta \mathrm{S}$ (that is $\approx 3$ ). The Se-O distances vary from $1.52(2) \AA$ to 1.74 (2) $\AA$, the $\mathrm{O}-\mathrm{Se}-\mathrm{O}$ angles are between $113.4(8)^{\boldsymbol{o}}$ and $119.9(8)^{\boldsymbol{o}}$; whereas at room temperature, the $\mathrm{Se}-\mathrm{O}$ distances are between 1.630(4) $\AA$ and 1.649(4) $\AA$, the $\mathrm{O}-\mathrm{Se}-\mathrm{O}$ angles values vary from $107.9(2)^{\mathrm{o}}$ to $110.6(3)^{\mathrm{o}}[15]$.

\section{III - Vibrational spectroscopy study:}

\section{III- 1- Vibrational spectroscopy study at room temperature:}

In order to confirm the presence and the independence of the anionic groups $\left(\mathrm{TeO}_{6}^{6-}, \mathrm{SeO}_{4}^{2-}\right)$, the vibrational study at room temperature was performed, the infrared and Raman spectra of this compound at room temperature, investigated in the frequency range of $400-4000 \mathrm{~cm}^{-1}$ and $50-1200 \mathrm{~cm}^{-1}$ respectively, are 
shown in Figure 8 and 9. The proposed assignments of the most important bands

Table 3 were carried out using data for similar selenate and tellurate compounds $[3,16-18]$.

\section{Interpretation of IR and Raman spectrum at room temperature:}

\section{- Vibration of $\mathrm{TeO}_{6}$ group :}

The $\mathrm{Te}(\mathrm{OH})_{6}$ group consists of $\mathrm{TeO}_{6}^{6-}$ anions and hydrogenic vibrations, the octahedral $\mathrm{TeO}_{6}$ has the following modes $v_{1}$ and $v_{3}$ are IR active, as well as the vibrations modes $v_{1}, v_{2}, v_{4}, v_{5}$ and $v_{6}$ are Raman active, the strong infrared band noticed at $663 \mathrm{~cm}^{-1}$ can be attributed to the symmetric stretching mode $v_{1}\left(\mathrm{TeO}_{6}\right)$. While the medium band observed in the infrared spectra at $592 \mathrm{~cm}^{-1}$ can be assigned to the asymmetric stretching vibration $v_{3}\left(\mathrm{TeO}_{6}\right)$, the strong band at 3428 $\mathrm{cm}^{-1}$ correspond to $v(\mathrm{Te}-\mathrm{OH})$ and the medium peak at $2417 \mathrm{~cm}^{-1}$ can be attributed to the hydrogen bending modes $v(\mathrm{OH})[17]$.

In $(\mathrm{CsSeTe})$ compound, all the octahedral vibrations modes are active in Raman except $v_{3}$. In fact, the most intense peaks around $650 \mathrm{~cm}^{-1}$ in Raman can be assigned to $v_{1}\left(\mathrm{TeO}_{6}\right)$, the vibration mode $v_{2}\left(\mathrm{TeO}_{6}\right)$ is distinguished by the medium Raman band at about $631 \mathrm{~cm}^{-1}$. Moreover, the two peaks detected at $366 \mathrm{~cm}^{-1}$ and $388 \mathrm{~cm}^{-1}$ correspond to $v_{4}\left(\mathrm{TeO}_{6}\right)$ vibration mode $[17,20,21]$, while the medium bands at 341 and $346 \mathrm{~cm}^{-1}$ are attributed to the $v_{5}$ vibration mode of $\left(\mathrm{TeO}_{6}\right)$ and the Raman peak around $221 \mathrm{~cm}^{-1}$ may be assigned to $v_{6}\left(\mathrm{TeO}_{6}\right)$. 


\section{- Vibration of $\mathrm{SeO}_{4}$ group :}

Vibrational analyses for the isolated $\mathrm{SeO}_{4}^{2-}$ anion exhibits following four normal vibrational modes: $v_{1}, v_{2}, v_{3}$ and $v_{4}\left(\mathrm{SeO}_{4}^{2-}\right)$, all of them are Raman active. The $v_{1}$ mode is the totally symmetric stretching vibrational mode of the $\mathrm{SeO}_{4}$ anion, $v_{2}$ is the doubly asymmetric degenerate bending mode, $v_{3}$ is the triply symmetric degenerate stretching mode and $v_{4}$ is the triply asymmetric degenerate bending mode [18]. The very strong peak around $824 \mathrm{~cm}^{-1}$ may be assigned to $v_{1}\left(\mathrm{SeO}_{4}\right)$ vibration mode, the line observed at $845 \mathrm{~cm}^{-1}$ can be attributed to the $v_{3}\left(\mathrm{SeO}_{4}\right)$ vibration mode, while the three peaks observed at 388,405 and $420 \mathrm{~cm}^{-1}$ are related to the triply degenerate bending mode $v_{4}\left(\mathrm{SeO}_{4}\right)[22,23]$.

The broad peaks at 439,449 and 452 are tentatively assigned to the doubling degenerate bending vibration mode $v_{2}\left(\mathrm{SeO}_{4}\right)$, as it detects by the intense band with frequency at $319 \mathrm{~cm}^{-1}[17,20,21]$. The tetrahedral $\mathrm{SeO}_{4}$ group has all the vibration modes which are infrared active, whereas only $v_{1}$ is inactive. The very strong IR band appeared at $866 \mathrm{~cm}^{-1}$ is attributed to the stretching $v_{3}\left(\mathrm{SeO}_{4}\right)$ and the band observed at $452 \mathrm{~cm}^{-1}$ are related to the vibration mode $v_{2}\left(\mathrm{SeO}_{4}\right)$, whilst the peak detected at $411 \mathrm{~cm}^{-1}$ is associated to the bending mode $v_{4}\left(\mathrm{SeO}_{4}\right)$.

\section{III -2 - Vibrational spectroscopy study at high temperature:}

To get more information about the crystal dynamics, on the degree of disorder and on the mechanisms involved in the transition at $320 \mathrm{~K}$ we have undertaken a 
Raman study in the temperature range from $293 \mathrm{~K}$ to $353 \mathrm{~K}$ and in the frequency region between $50-1200 \mathrm{~cm}^{-1}$ see Figure 10 .

To validate the probable transformation in the spectra around the $320 \mathrm{~K}$ phase transition, the vibrational analyses of the broad temperature range have also been taken to obtain further information about the role of anion contributions to the mechanism of the phase transition in the (CsSeTe) compound.

For this reason, the detailed analyses of position, intensity and width at half height of the bands have been carried out at temperature before and after the phase transition temperature. Since the wave number region associated with the bands emanating from the vibration modes of the anionic units, the changes are likely to correspond with the different dynamical state of both ions below and above the phase transition detected at $\mathrm{T}=320 \mathrm{~K}$.

The aforementioned analysis clearly indicates that there are significant changes in the position, intensity and half width of the bands corresponding to the internal vibrations modes when the temperature increases to $353 \mathrm{~K}$.

In the vicinity range of the order - disorder phase transition detected by DSC at $\mathrm{T}=320 \mathrm{~K}$, all the bands exhibit a change in their position at higher frequencies. Therefore, the phase transition detected at $\mathrm{T}=320 \mathrm{~K}$ has been proven in the compound by Raman spectroscopy. In order to quantitatively analyze the evolution of Raman bands versus temperature, the position, intensity and half 
width of the Raman lines were deconvoluated by Labspec software using a combination of Gaussian and Lorentzian functions [24].

Figures $11(\mathrm{a}, \mathrm{b})$ indicate the deconvolutions of the room temperature at [500 700] $\mathrm{cm}^{-1}$ and $[700-900] \mathrm{cm}^{-1}$ spectra ranges, respectively. They demonstrate that there is only one type of octahedron and one type of tetrahedron that's why we observe only one maximum at $650.2 \mathrm{~cm}^{-1}$ and $824.6 \mathrm{~cm}^{-1}$ respectively at $\mathrm{T}=298 \mathrm{~K}$.

Figure 12 (a) report the temperature dependence of position vibration modes related to octahedron group in the ( $\mathrm{CsSeTe})$ material, the lines issued from the internal vibrations modes of the $\mathrm{TeO}_{6}^{6-}$ anions shift to higher frequencies when the temperature increases from 298 to $353 \mathrm{~K}$. The position shift of the bands associated with $v_{2}\left(\mathrm{TeO}_{6}\right), v_{5}\left(\mathrm{TeO}_{6}\right)$ and $v_{6}\left(\mathrm{TeO}_{6}\right)$ vibration modes conserves its linear aspect and becomes discontinuous when the temperature comes closer to the phase transition temperature at $\mathrm{T}=320 \mathrm{~K}$, the position shift of these lines range approximately from 5,10 and $20 \mathrm{~cm}^{-1}$ for $v_{2}\left(\mathrm{TeO}_{6}\right), v_{5}\left(\mathrm{TeO}_{6}\right)$ and $v_{6}\left(\mathrm{TeO}_{6}\right)$, respectively.

In fact, all the bands lose their linear character around a transition temperature, the temperature of discontinuity detected at $\mathrm{T}=320 \mathrm{~K}$ is assumed to be the temperature of the phase transition [24], which is in accordance with the DSC result. Above $330 \mathrm{~K}$, all the bands recover their linearity. 
By visualizing Figure 12 (b), when the temperature grows, all the analyzed bands of the vibration modes of $\mathrm{TeO}_{6}^{6-}$ increase in intensity at $320 \mathrm{~K}$ except that $v_{5}$ $\left(\mathrm{TeO}_{6}\right)$ suffer a decrease in intensity. Indeed, the valence intensity bands $v_{1}, v_{2}$, $v_{5}$ and $v_{6}\left(\mathrm{TeO}_{6}\right)$ undergo a significant discontinuous shift above the transition, which can be attributed to a more important disordered phase, and thus to an order - disorder phase transition on heating [25-27]. Most of the lines also exhibit a slightly more important shift from about 50, 250, 300 and $900 \mathrm{~cm}^{-1}$ for $v_{1}, v_{2}, v_{6}$ and $v_{5}\left(\mathrm{TeO}_{6}\right)$, respectively.

The temperature b-ehavior of same Raman half widths is presented in Figure 12 (c). We notice an important variation of the half widths when the temperature increases, in fact this phenomenon is clearly visible in the vibrations modes $v_{1}, v_{4}$ and $v_{5}\left(\mathrm{TeO}_{6}\right)$, these Raman bands broaden at high temperature and more precisely in the phase transition temperature.

While the growth in temperature induces the decrease in half width about $70 \mathrm{~cm}^{-1}$ for the vibration mode $v_{5}\left(\mathrm{TeO}_{6}\right)$ and the increase in half widths nearly 3.5 and $17.5 \mathrm{~cm}^{-1}$ for the vibration modes $v_{1}$ and $v_{4}\left(\mathrm{TeO}_{6}\right)$, respectively.

This behavior can be clarified by the dynamic disorder of the $\mathrm{TeO}_{6}$ anionic group $[24,25]$.

The temperature effect can also be seen in the temperature dependence of the position vibration modes related to tetrahedron group in the (CsSeTe) material. 
Figure 13(a) shows a significant transformation of the symmetrical and antisymmetric elongation vibrations $v_{1} \quad\left(\mathrm{SeO}_{4}\right)$ and $v_{3} \quad\left(\mathrm{SeO}_{4}\right)$ become discontinuous and lose their linearity at $\mathrm{T}=320 \mathrm{~K}$. On the other hand, the deformation vibration $v_{2}\left(\mathrm{SeO}_{4}\right)$ and $v_{4}\left(\mathrm{SeO}_{4}\right)$ broaden with an increase in temperature, the shift of these bands approximately change from 90 to $50 \mathrm{~cm}^{-1}$ for $v_{2}$ and $v_{4}\left(\mathrm{SeO}_{4}\right)$.

By increasing temperature from $298 \mathrm{~K}$ to $340 \mathrm{~K}$, all the bands associated with the vibration modes of $\mathrm{SeO}_{4}$ group show major variations of intensity, especially when the temperature reflects the temperature of the phase transition shown in Figure 13(b).

The intensity shift of the bands corresponding to $v_{1}\left(\mathrm{SeO}_{4}\right), v_{2}\left(\mathrm{SeO}_{4}\right), v_{3}\left(\mathrm{SeO}_{4}\right)$ and $v_{4}\left(\mathrm{SeO}_{4}\right)$ ranges from about $700,1820,1550$ and $900 \mathrm{~cm}^{-1}$, major intensity shift of these bands around the phase transition detected at $\mathrm{T}=320 \mathrm{k}$ is observed. Consequence of an order -disorder phase transition, this behavior was interpreted as the occupation of three possible positions by the both polyhedrons [27].

Effectively, at high temperature the octahedron and the tetrahedron occupy three different positions, as described in the structural study and confirmed by the entropy study.

Figure 13(c) shows a significant transformation of the half width bands that correspond to the vibrations modes of the $\mathrm{SeO}_{4}$ group, when the temperature comes close to the phase transition temperature at $320 \mathrm{~K}$, the line corresponding 
to $v_{2}\left(\mathrm{SeO}_{4}\right)$ reveals an important change in the half width, the movement to higher frequencies at $320 \mathrm{~K}$ and shift up to $50 \mathrm{~cm}^{-1}$ proving the presence of the order disorder phase transition [24, 26].

According to the structural study, the tetrahedral changing orientation while keeping the same position and the central atom of the octahedron occupies three adjacent positions. It may be thought that the observed phase transition (320K) is related to the reorientation and the translation dynamical disordered of the selenate and tellurate groups.

\section{Conductivity behavior:}

The thermal evolution of conductivity for the (CsSeTe) material is presented in Figure 14 the plot of this figure shows the evolution of the conductivity versus inverse temperature $(\log (\sigma \mathrm{T}))=\mathrm{f}(1000 / \mathrm{T})$ which is in the temperature range 384 $-625 \mathrm{~K}$. In fact, in the three linear regions of the curve the Arrhenius type behavior $\sigma \mathrm{T}=\sigma_{0} \exp \left(-\mathrm{E}_{\mathrm{a}} / \mathrm{KT}\right)$ is observed, revealing the conductivity phase transition in this material [3]. Characterizes the low and the high temperature domain with a sudden jump increase of the conductivity up to $490 \mathrm{~K}$.

The first region, between 403 and $444 \mathrm{~K}$, characterizes the low temperature conduction with the activation energy $\Delta \mathrm{E}_{1}=0.065 \mathrm{eV}$. Furthermore, the second temperatures range, from 444 to $495 \mathrm{~K}$. The third region is between 495 and $543 \mathrm{~K}$ characterizes the high temperature conduction with the activation energy $\Delta \mathrm{E}_{2}=0.18 \mathrm{eV}$. The conductivity increases from $\sigma_{1} \mathrm{~T}=2.23 \times 10^{-2} \mathrm{~K} \Omega^{-1} \mathrm{~m}^{-1}$ at $403 \mathrm{~K}$ 
to $\sigma_{2} \mathrm{~T}=1.85 \times 10^{-2} \mathrm{~K}^{-1} \mathrm{~m}^{-1}$ at $543 \mathrm{~K}$. So, this compound is a super ionic- protonic one, due to the breaking of $\mathrm{O}-\mathrm{H} . . . \mathrm{O}$ hydrogen bond firstly, and the reorientation of polyhedra already detected by Raman and structural study on the other hand. [28].

\section{Conclusion:}

The differential scanning calorimetry (DSC) analysis shows the presence of the phase transition at $\mathrm{T}=320 \mathrm{~K}$, the observed value of the entropy $\Delta \mathrm{S}$ probably reflects the reorientation of the selenate and tellurate groups.

In the structure of this material, the temperature increase leads to noticeable changes. In fact, space group changes from $\mathrm{P} 2{ }_{1} / \mathrm{c}$ to $\mathrm{R} \overline{3} \mathrm{~m}$, on the other hand $\mathrm{SeO}_{4}$ tetrahedra become disordered by rotation among 3 positions. However, in the $\mathrm{TeO}_{6}$ polyhedra the tellurium atom occupies three adjacent positions. Analysis of crystal structure shows that $\mathrm{TeO}_{6}$ and $\mathrm{SeO}_{4}$ polyhedra are main disordered units in the structure. In this respect, the structure before phase transition remains ordered and further disordering of $\mathrm{TeO}_{6}$ and $\mathrm{SeO}_{4}$ polyhedra can be found at high temperature.

Raman analysis at different temperatures confirms the results detected by DSC, the structural study and proves that the transition at $\mathrm{T}=320 \mathrm{~K}$ is an order- disorder type of orientation polyhedra, it can also be structural phase transition. 
we remark a strong jump detected at $495 \mathrm{~K}$ in the conductivity plot characterizes a super-protonic conduction accompanied by the breaking of hydrogen bonds which link all the polyhedra in our material structure.

\section{Acknowledgements}

The authors do thank the members of units of common services at the University of Sfax, for their commendable efforts. The authors are also grateful to Dr. Hamadi KHEMAKHEM for his help in the spectroscopies Raman measurements. The authors are also thankful to Mr. Ozhan HAMMAMI for the checking and grammatical editing of this article in English. 


\section{References:}

1. Litaiem H, Grasia-Granda S, Ktari L, Dammak M. The structural behaviour before the ionic-protonic superconduction phase transition and thermal properties in the caesium sulphate arsenate tellurate compound. J Therm Anal Calorim. 2015; 123: 391-400.

2. Litaiem H, Dammak M, Mhiri T, Cousson A. Structural, conductivity and dielectric studies in $\left(\mathrm{NH}_{4}\right)_{2} \mathrm{SeO}_{4} \cdot \mathrm{Te}(\mathrm{OH})_{6}$. J Alloy Compd. 2005; 396: 34-39.

3. Dammak M, Litaiem H, Mhiri T. Structural, thermal and dielectric studies in $\mathrm{Na}_{2} \mathrm{SeO}_{4} \cdot \mathrm{Te}(\mathrm{OH})_{6} . \mathrm{H}_{2} \mathrm{O}$. J Alloy Compd. 2006; 416: 228-235.

4. Dammak M, Litaiem H, Gravereau P, Mhiri T, Kolsi A W. X-ray and electrical conductivity studies in the rubidium selenate tellurate. J Alloy Compd. 2007; 442: $316-319$.

5. CrysAlis CCD and CrysAlis RED. Yarnton, Oxfordshire: Oxford Diffraction Ltd; (2010).

6. Sheldrick GM. SHELXS97: program for the refinement of crystal structures. Germany: University of Gottingen; (1986).

7. Sheldrick GM. SHELXL97: program for the refinement of crystal structures. Germany: University of Gottingen; (1997).

8. Putz H, Brandenburg K, DIAMOND Version 3.2.i, Crystal Impact, Gb R, Kreuzherrenstr, Germany (1997-2012).

9. Sharlo G, Methods of analytical chemistry. Moscow, Inostrannaya literatira publ. House; (1969).

10. Azaroval L, Burger M, X- ray pouder method. Moscow, Peace; (1961). 
11. Baur W H. The Geometry of Polyhedral Distortions Predictive Relationships for the Phosphate Group. Acta Crystal. 1974 ; B 30 : 1195-1215.

12. Piecha A, Gagar A, Pietraszko A, Jakubas R. Unprecedented solid-state chemical reaction-from $\left(\mathrm{C}_{3} \mathrm{~N}_{2} \mathrm{H}_{5}\right)_{3} \mathrm{SbBr}_{6} \cdot \mathrm{H}_{2} \mathrm{Oto}\left(\mathrm{C}_{3} \mathrm{~N}_{2} \mathrm{H}_{5}\right)_{5} \mathrm{Sb}_{2} \mathrm{Br}_{11}$. From centrosymmetric to non-centrosymmetric crystal structure. Solid State Chem. 2010; 183: 3058-3066.

13. Fabry J, Loub J, Feltl L. A study of the thermal decompositions of orthotelluric acid, urea and the orthotelluric acid adduct with urea. J Therm Anal. 1982; 24: 95-100.

14. Jiao QJ, Zhu YL, Xing JC, Ren H, Huang H. Thermal decomposition of RDX/AP by TG-DSC-MS-FTIR. J Therm Anal Calorim. 2014;116:1125-31.

15. Dammak M, Mhiri T, Jaud J, Savariault J M. Structural study of the two new caesium sulfate and selenate tellurate $\mathrm{Cs}_{2} \mathrm{SO}_{4} \cdot \mathrm{Te}(\mathrm{OH})_{6}$ and $\mathrm{Cs}_{2} \mathrm{SeO}_{4} \cdot \mathrm{Te}(\mathrm{OH})_{6}$. Inorg Mater. 2001; 3: 861-873.

16. Ghorbel K, Litaiem H, Ktari L, Grasia-Granda S, Dammak M. X-ray single crystal, thermal analysis and vibrational study of $\left(\mathrm{NH}_{4}\right)_{2}\left(\mathrm{SO}_{4}\right)_{0.92} \mathrm{H}\left(\mathrm{AsO}_{4}\right)_{0.08}$. Te $(\mathrm{OH})_{6}$.Mol Struct. 2015; 1079: 225-231.

17. Litaiem H, Dammak M, Ktari L, Kammoun S, Mhiri T. Phase transitions and vibrational study of $\mathrm{Rb}_{2} \mathrm{SeO}_{4} \cdot \mathrm{Te}(\mathrm{OH})_{6}$ and $\mathrm{Rb}_{1.12}\left(\mathrm{NH}_{4}\right)_{0.88} \mathrm{SO}_{4} \cdot \mathrm{Te}(\mathrm{OH})_{6}$. Phase Transit. 2004; 77: 929-940.

18. Ghorbel K, Litaiem H, Ktari L, Grasia-Granda S, Dammak M. Synthesis, Structural Study and Phase Transitions Characterization by Thermal Analysis and 
Vibrational Spectroscopy of an Ammonium Rubidium Arsenate Tellurate. Chem Res Chin Univ. 2016; 32: 902-911.

19. Frost R L, Sejkora C J, Plasil J, Reddy B J, Keeffe E C. Raman spectroscopic study of a hydroxy-arsenate mineral containing bismuth-atelestite $\mathrm{Bi}_{2} \mathrm{O}(\mathrm{OH})\left(\mathrm{AsO}_{4}\right)$. Spectroc Acta. 2011; 78: 494-496.

20. Dammak M, Kemakhem H, Mhiri T, Kolsi A W, Daoud A. Structural and Vibrational Study of $\mathrm{K}_{2} \mathrm{SeO}_{4} \cdot \mathrm{Te}(\mathrm{OH})_{6}$ Material. Solid State Chem. 1999; 145 : $612-618$.

21. Dammak M, Hadrich A, Mhiri T. Structural, dielectric and vibrational studies in the dipotassium sulfate selenate tellurate mixed solid solution. J Alloy Compd. 2007; 428: 8-16.

22. Jrifi A, El Jazouli A, Chaminade J P, Couzi M. Synthesis, crystal structure and vibrational spectra of $\mathrm{Sr}_{0.5} \mathrm{Zr}_{2}\left(\mathrm{AsO}_{4}\right)_{3}$. Powder Diffr. 2009; 24: 200-204.

23. Frost R L. Raman and infrared spectroscopy of arsenates of the roselite and fairfieldite mineral subgroups. Spectroc Acta. 2009; 71: 1788-1794.

24. Fersi M A, Chaabane I, Gargouri M, Bulou A. Raman scattering study of temperature induced phase transition in $\left[\mathrm{C}_{8} \mathrm{H}_{10} \mathrm{NO}\right]_{2}\left[\mathrm{ZnCl}_{4}\right]$. AIP ADV. 2015; 5: 087127.

25. Ben Gzaiel M, Ouslati A, Lhoste J, Gargouri M. Synthesis, crystal structure and high temperature phase transition in the new organic-inorganic hybrid $\left[\mathrm{N}\left(\mathrm{C}_{4} \mathrm{H}_{9}\right)_{4}\right]_{3} \mathrm{Zn}_{2} \mathrm{Cl}_{7} \mathrm{H}_{2} \mathrm{O}$ crystal. J Mol Struct. 2015; 1089: 153-160. 
26. Hajlaoui S, Chaabane I, Ouslati A, Guidra K, Bulou A. Raman scattering investigation of the high temperature phase transition in $\left.\left[\mathrm{N}_{\left(\mathrm{C}_{3}\right.} \mathrm{H}_{7}\right)_{4}\right]_{2} \quad \mathrm{SnCl}_{6}$. Spectroc Acta A. 2015; 136: 457-552.

27. Ben Salah M, Becker P, Carabatos-Nédelec C. Raman studies of orderdisorder phase transition in sodium p-nitrophenolate dihydrate $(\mathrm{NPNa})\left[\mathrm{Na}\left(\mathrm{C}_{6}\right.\right.$ $\left.\left.\mathrm{H}_{4} \mathrm{ONO}_{2}\right)\right]_{2} \mathrm{H}_{2} \mathrm{O}$. single crystal. Vib Spectros. 2003; 31: 187-193.

28. Mtioui O, Litaiem H, Garcia-Granda S, Ktari L, Dammak M. Thermal behavior and dielectric and Vibrational studies of $\mathrm{Cs}_{2}\left(\mathrm{HAsO}_{4}\right)_{0.32}\left(\mathrm{SO}_{4}\right)_{0.68}$ · $\mathrm{Te}(\mathrm{OH})_{6}$. Ionics. 2014; 21: 411-420. 


\section{Table captions:}

Table 1: The chemical analysis results of $\mathrm{Cs}_{2} \mathrm{SeO}_{4} \cdot \mathrm{Te}(\mathrm{OH})_{6}$ compound.

Table 2: Main crystallographic feature, X-ray diffraction data parameters results of $\mathrm{Cs}_{2} \mathrm{SeO}_{4} \cdot \mathrm{Te}(\mathrm{OH})_{6}$ compound.

Table 3: Infrared and Raman data for $\mathrm{Cs}_{2} \mathrm{SeO}_{4} \cdot \mathrm{Te}(\mathrm{OH})_{6}$ material at room temperature. 


\section{Figure captions:}

Figure 1: The EDS spectrum of the $\mathrm{Cs}_{2} \mathrm{SeO}_{4} \cdot \mathrm{Te}(\mathrm{OH})_{6}$ compound.

Figure 2: The SEM fracture micrograph of the $\mathrm{Cs} 2 \mathrm{SeO} 4 . \mathrm{Te}(\mathrm{OH})_{6}$ material.

Figure3: DSC curve of $\mathrm{Cs}_{2} \mathrm{SeO}_{4} \cdot \mathrm{Te}(\mathrm{OH})_{6}$ material.

Figure 4: Arrangement of polyhedra in CsSeTe material at $\mathrm{T}=360 \mathrm{~K}$.

Figure 5: Tellurate polyhedron in CsSeTe compound.

Figure 6: Selenate polyhedron in CsSeTe compound.

Figure 7: One position of the $\mathrm{SeO}_{4}$ tetrahedron at $\mathrm{T}=360 \mathrm{~K}$.

Figure 8: IR spectrum of the CsSeTe compound at room temperature.

Figure 9: Raman spectra of the CsSeTe compound at room temperature.

Figure 10: Raman spectra of the CsSeTe compound at different temperatures.

Figure $11(\mathbf{a}, \mathbf{b})$ : Raman spectrum deconvolution of the CsSeTe compound.

Figure $12(\mathbf{a}, \mathbf{b}, \mathbf{c})$ : The temperature dependence of the position, intensity and half- width vibrations modes respectively related to octahedron group in the CsSeTe material.

Figure $13(\mathbf{a}, \mathbf{b}, \mathbf{c})$ : The temperature dependence of the position, intensity and half- width vibrations modes respectively related to tetrahedron group in the CsSeTe material.

Figure 14: Teperature dependence of $(\log (\sigma \mathrm{T}))$ for $(\mathrm{CsSeTe})$. 
Table 1

Compound Theoretically calculated mass \% $\quad$ Obtained by chemical analysis mass \%

$\begin{array}{ccc}\text { Te } & 20.09 & 18.13 \\ \text { Se } & 11.78 & 11.21 \\ \mathrm{Cs} & 41.82 & 38.35 \\ \mathrm{H}_{2} \mathrm{O} & 26.31 & -\end{array}$


Table 2

Chemical formula

$\mathrm{Cs}_{2} \mathrm{SeO}_{4} \cdot \mathrm{Te}(\mathrm{OH})_{6}$

Color/shape

Colourless/parallelepiped

Temperature/K

$360 \mathrm{~K}$

Crystal system

trigonal

Space group

$\mathrm{a} / \AA$

$\mathrm{R} \overline{3} \mathrm{~m}$

$\mathrm{b} / \AA$

$7.5345(8)$

$\mathrm{c} / \AA$

$7.5345(8)$

$\gamma /\left({ }^{\circ}\right)$

$8.5541(10)$

$\mathrm{V} /\left(\AA^{3}\right)$

120

$420.55(8)$

$\mathrm{F}(000)$

1128

Formula weight $/\left(\mathrm{g} \cdot \mathrm{mol}^{-1}\right) \quad 638.43$

$\mu / \mathrm{mm}^{-1}$

16.44

Min/max Brag angle $/\left(^{\circ}\right)$

$5.41 / 30.49$

Index ranges

$-10 \leqslant \mathrm{~h} \leqslant 6,-3 \leqslant \mathrm{k} \leqslant 10,-12 \leqslant 1 \leqslant 7$

Parameters refined

31

Independent reflections 333

GOOF

0.977

$\mathrm{R} 1[\mathrm{~F} 2>4 \sigma(\mathrm{F}) 2]$

0.028

wR2(F2)

0.031

$\Delta \rho \min \left(\mathrm{e}^{-3}\right) / \Delta \rho \max \left(\mathrm{e}^{-3}\right)-0.413 / 0.414$ 
Table 3

\begin{tabular}{|c|c|c|}
\hline$I R, v / \mathbf{c m}^{-1}$ & Raman shift $/ \mathrm{cm}^{-1}$ & Assignment \\
\hline $3428 \mathrm{~s}$ & - & $v(\mathrm{Te}-\mathrm{OH})$ \\
\hline $2417 \mathrm{sh}$ & _ & $v(\mathrm{OH})$ \\
\hline $1643 \mathrm{~s}$ & - & - \\
\hline $1328 \mathrm{sh}$ & - & - \\
\hline $1123 \mathrm{sh}$ & _ & _ \\
\hline 866 vs & 845 br & $v_{3}\left(\mathrm{SeO}_{4}\right)$ \\
\hline - & 824 vs & $v_{1}\left(\mathrm{SeO}_{4}\right)$ \\
\hline 663 vs & $650 \mathrm{vs}$ & $v_{1}\left(\mathrm{TeO}_{6}\right)$ \\
\hline _ & $631 \mathrm{~m}$ & $v_{2}\left(\mathrm{TeO}_{6}\right)$ \\
\hline $592 \mathrm{sh}$ & _ & $v_{3}\left(\mathrm{TeO}_{6}\right)$ \\
\hline \multirow[t]{3}{*}{$452 \mathrm{~m}$} & 452 br & \\
\hline & $449 \mathrm{br}$ & $v_{2}\left(\mathrm{SeO}_{4}\right)$ \\
\hline & $439 \mathrm{br}$ & \\
\hline $411 \mathrm{~m}$ & $420 \mathrm{~m}$ & $v_{4}\left(\mathrm{SeO}_{4}\right)$ \\
\hline - & $405 \mathrm{~s}$ & \\
\hline- & $388 \mathrm{~m}$ & $v_{4}\left(\mathrm{TeO}_{6}\right)+v_{4}\left(\mathrm{SeO}_{4}\right)$ \\
\hline - & $366 \mathrm{~m}$ & \\
\hline - & $341 \mathrm{~m}$ & $v_{5}\left(\mathrm{TeO}_{6}\right)$ \\
\hline - & $346 \mathrm{~m}$ & \\
\hline- & $319 \mathrm{~s}$ & $v_{2}\left(\mathrm{SeO}_{4}\right)$ \\
\hline - & $221 \mathrm{~m}$ & $v_{6}\left(\mathrm{TeO}_{6}\right)$ \\
\hline
\end{tabular}

Relative intensities: s: strong; vs: very strong; sh: shoulder; m: medium; br: broad. 


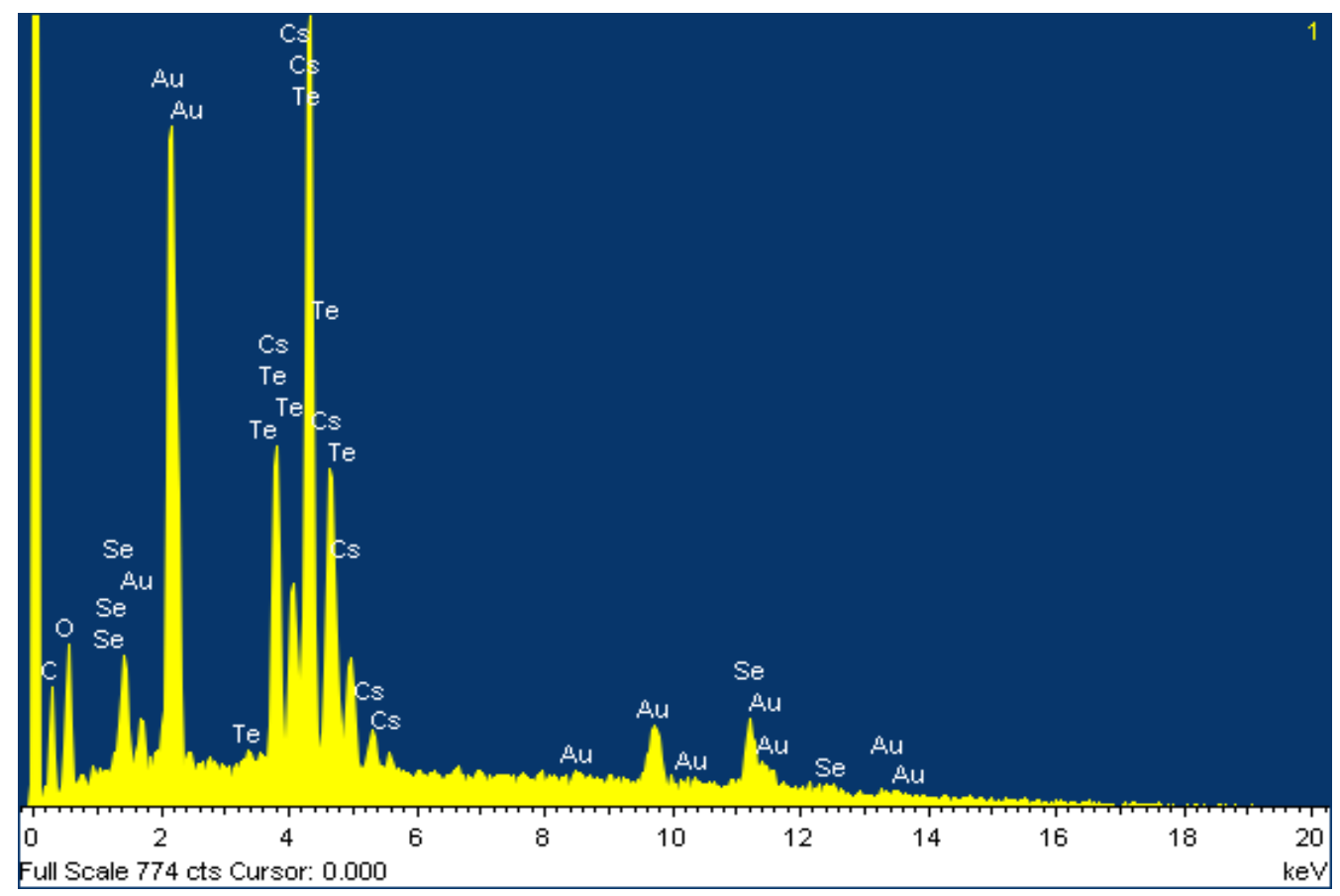

Figure 1

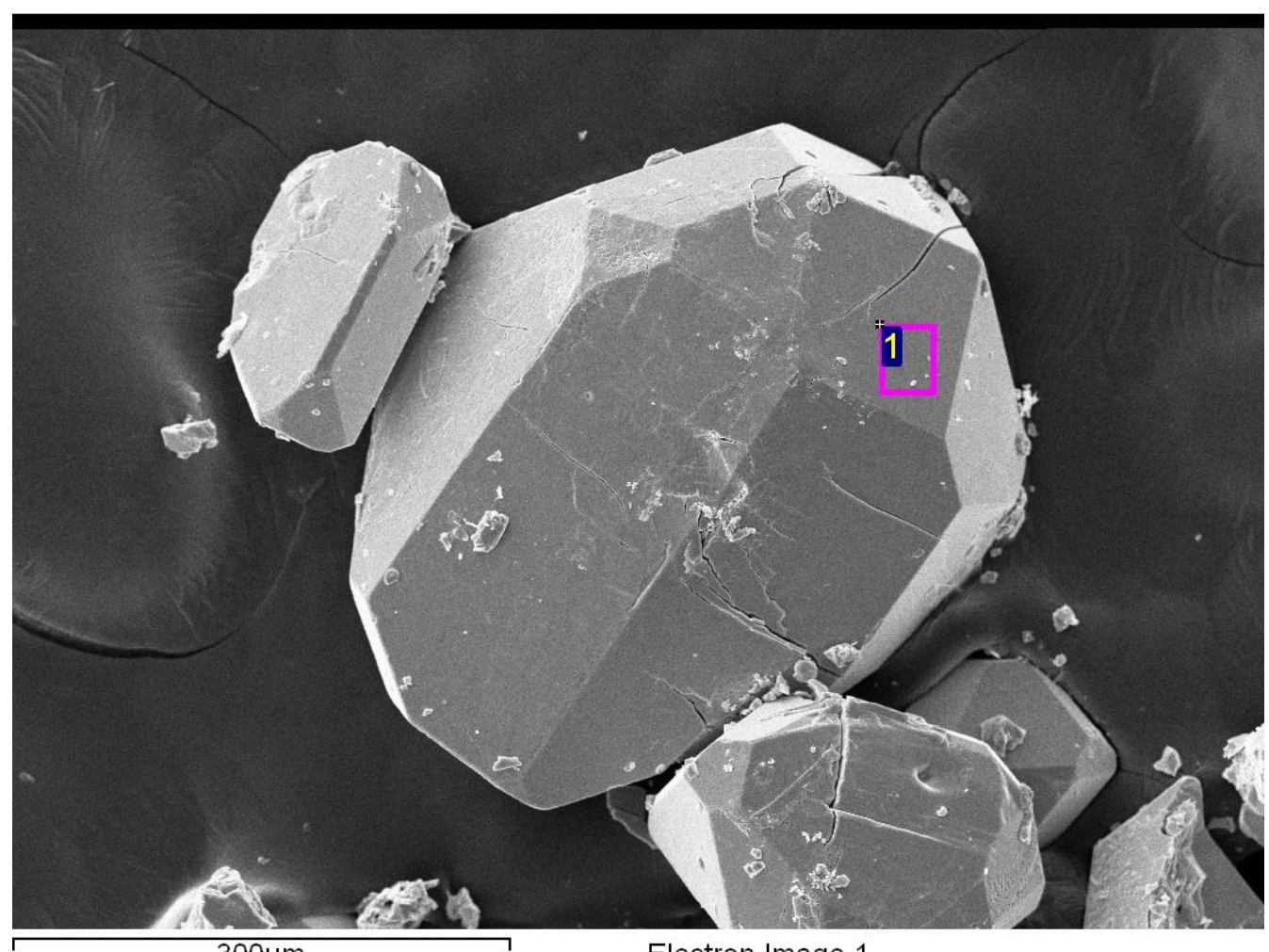

$300 \mu \mathrm{m}$

Electron Image 1

Figure 2 


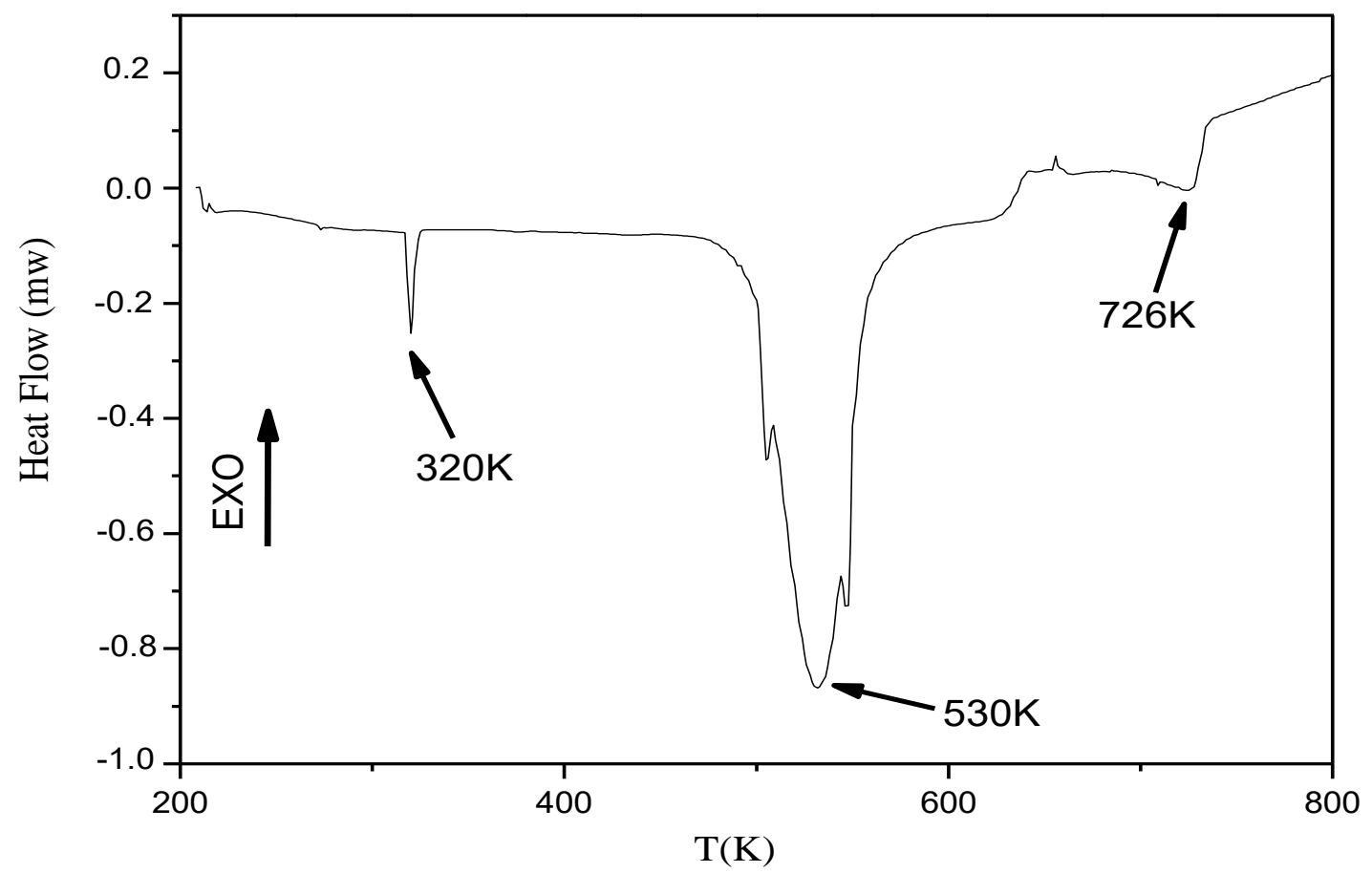

Figure 3

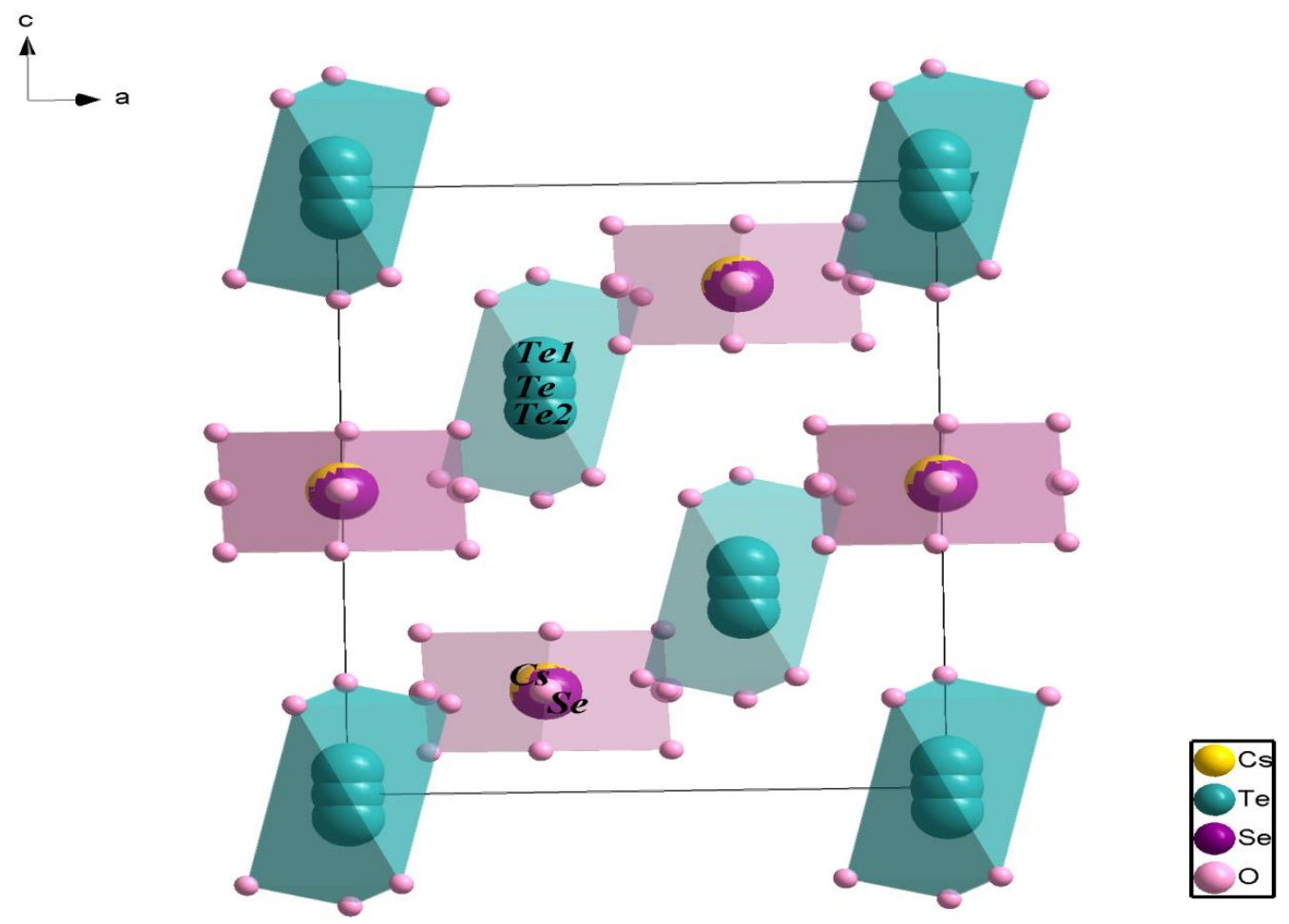

Figure 4 


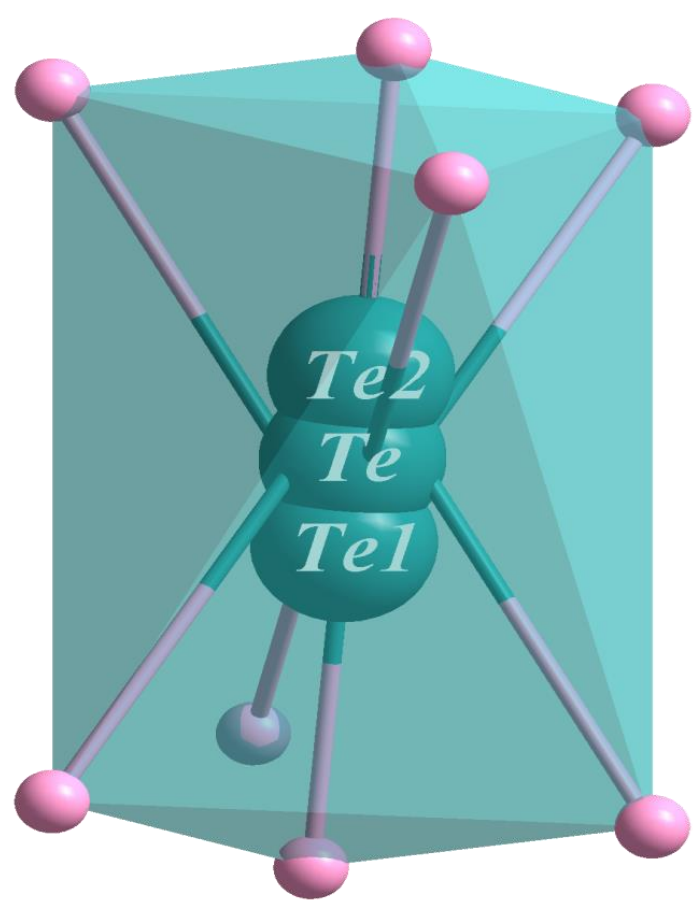

Figure 5

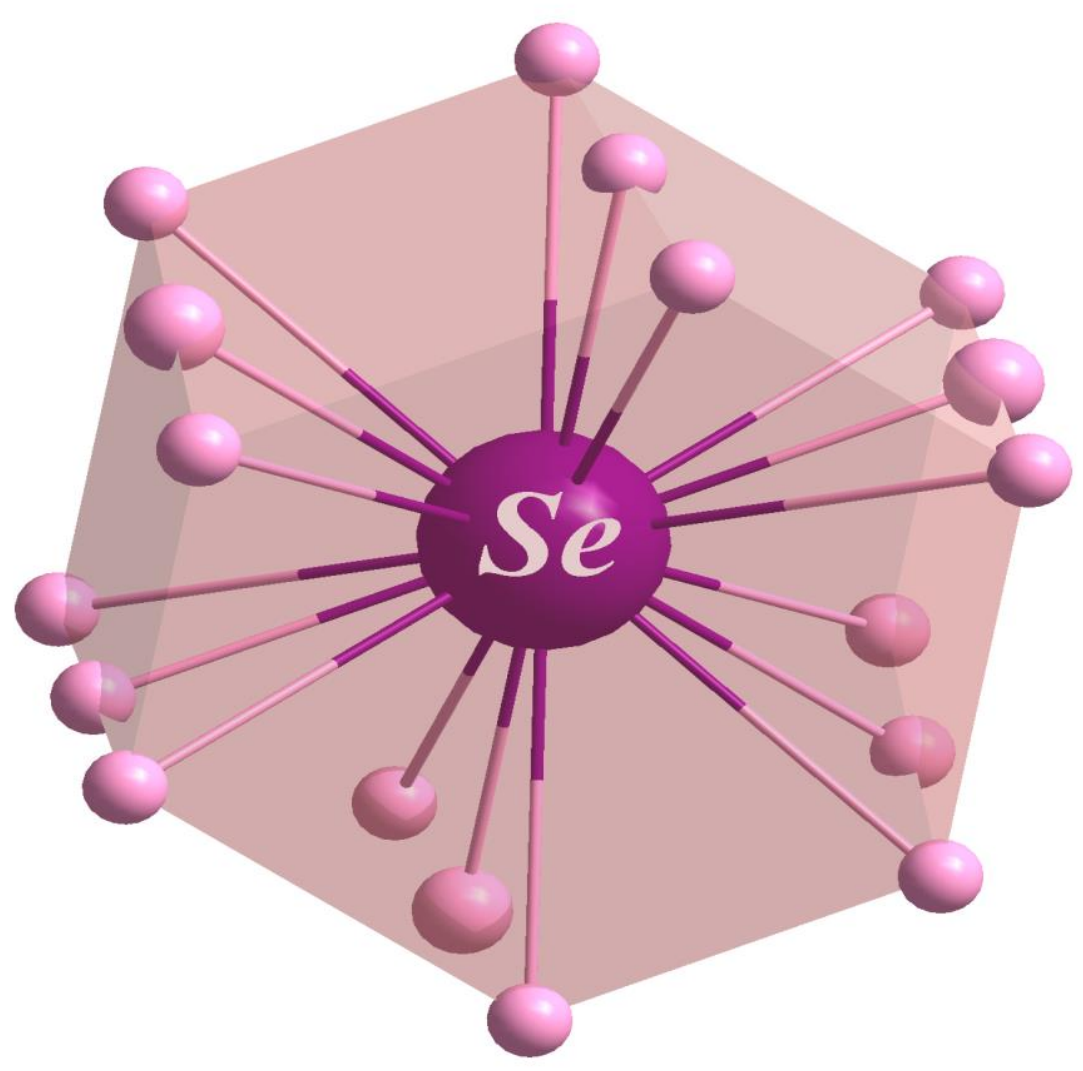

Figure 6 


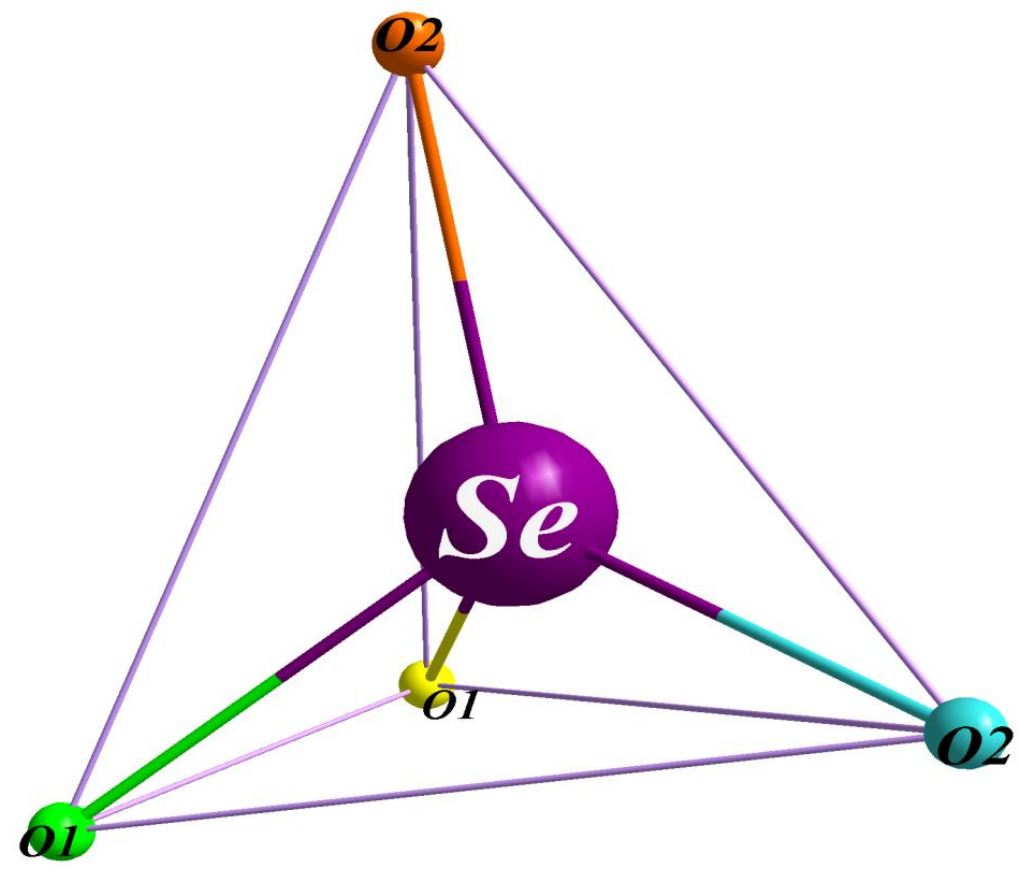

Figure 7

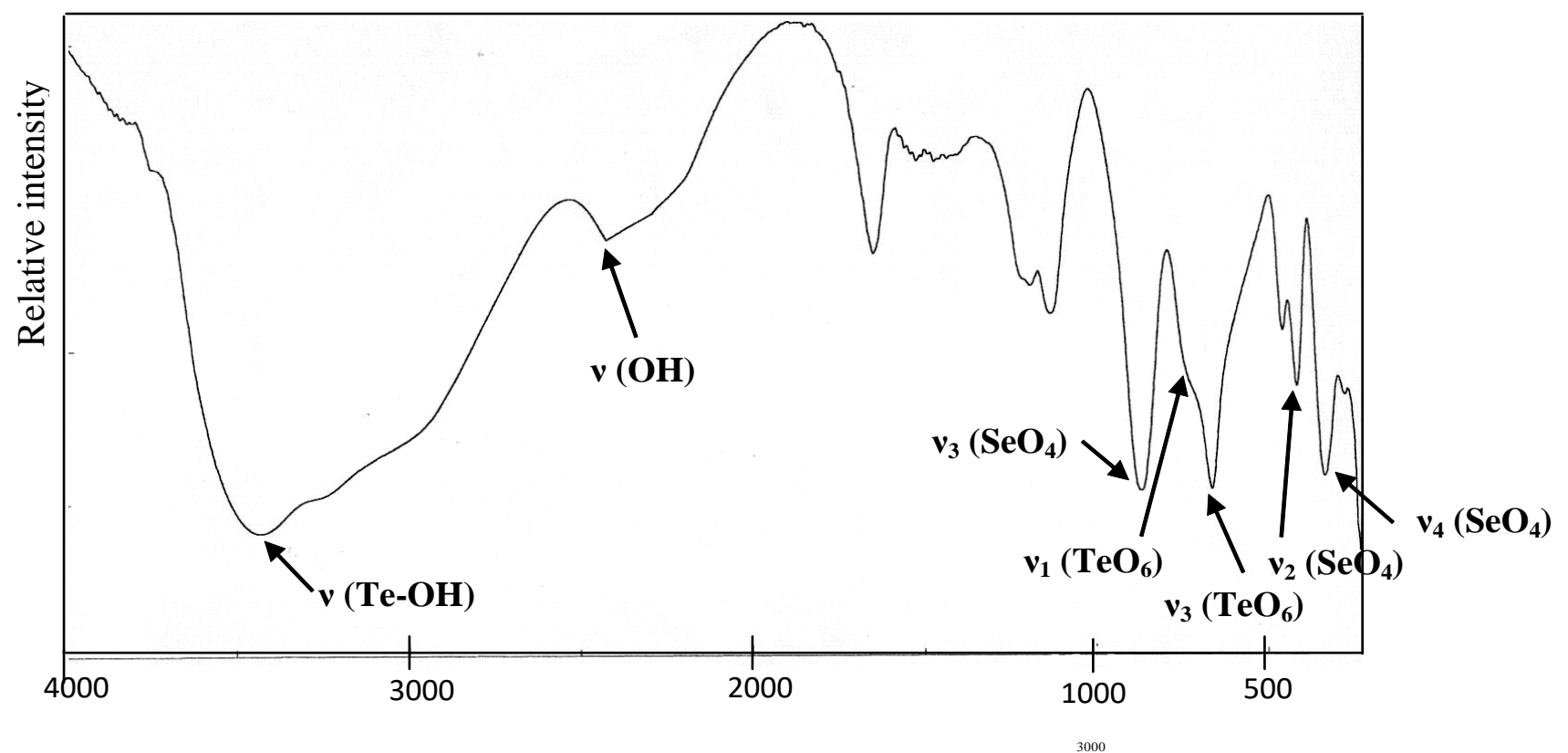

Wave number $\left(\mathrm{cm}^{-1}\right)$

Figure 8 


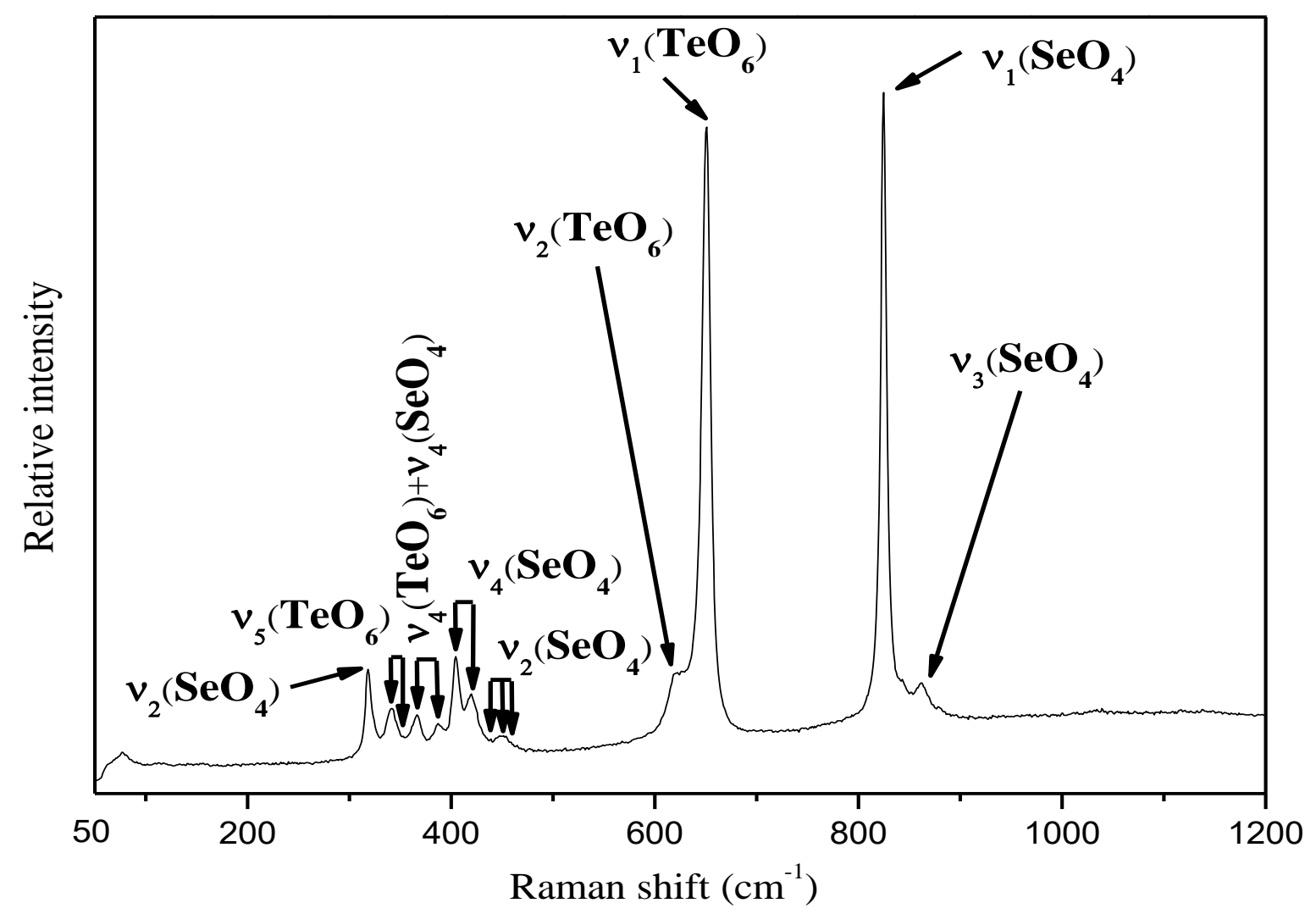

Figure 9 


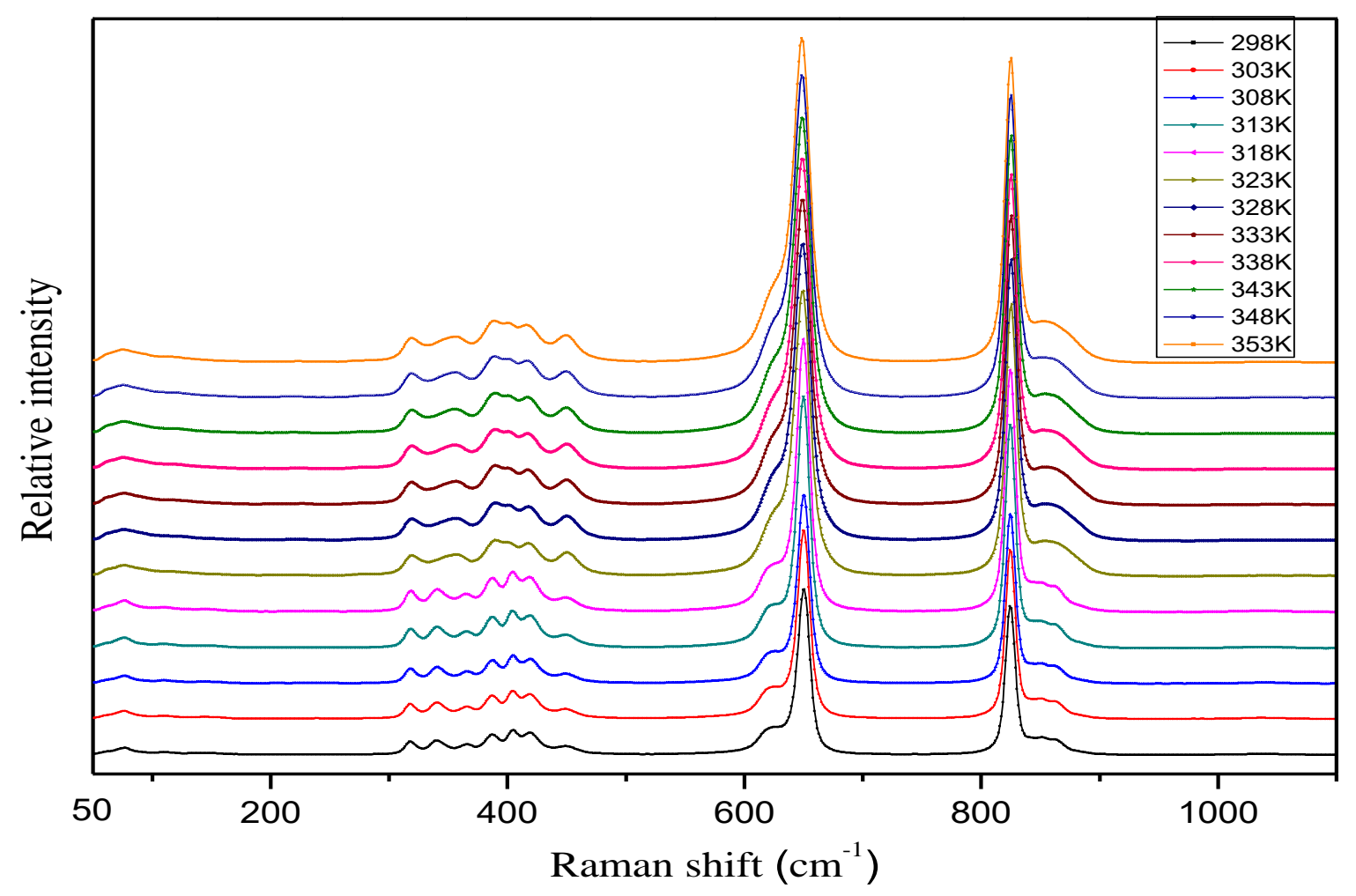

Figure 10 


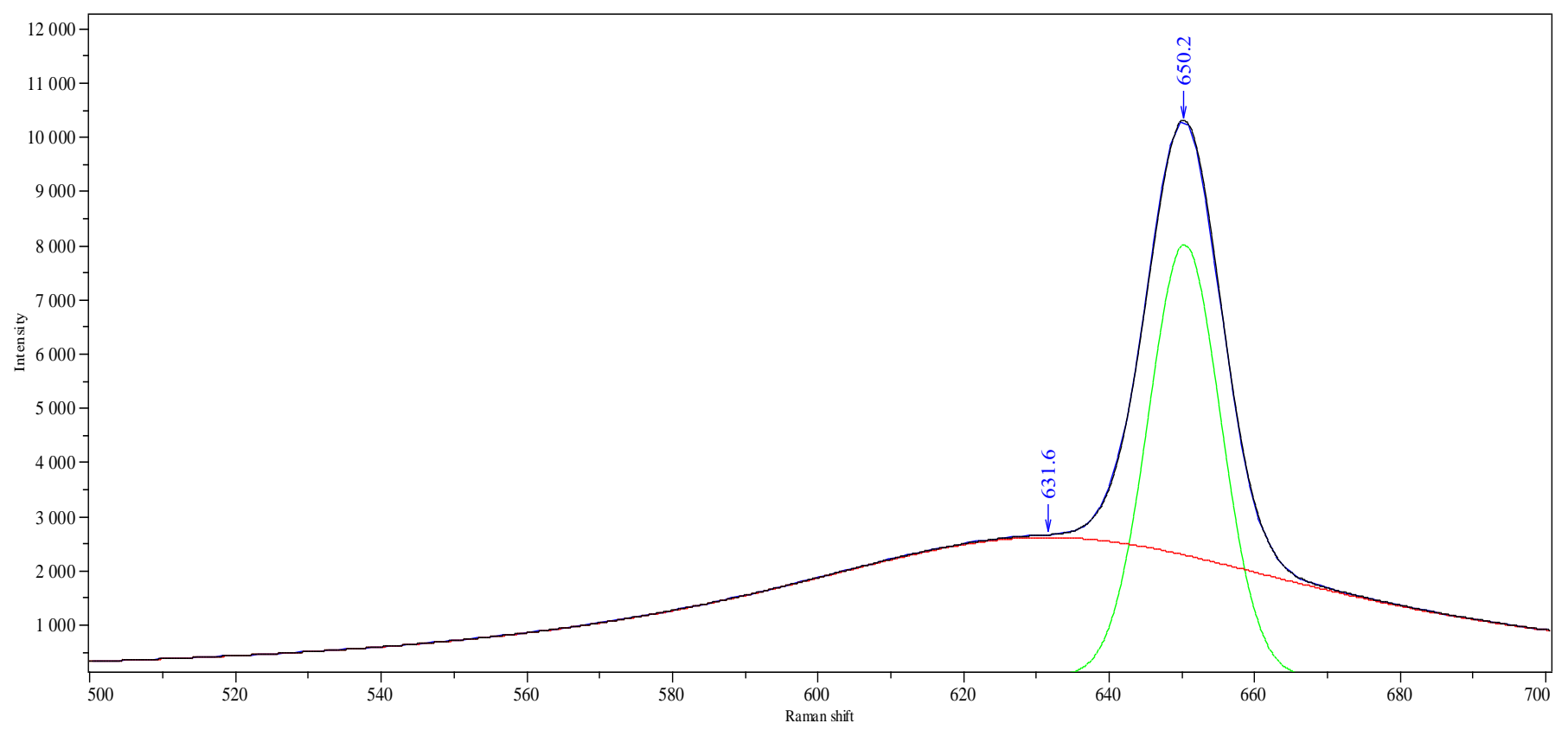

Figure 11- a 


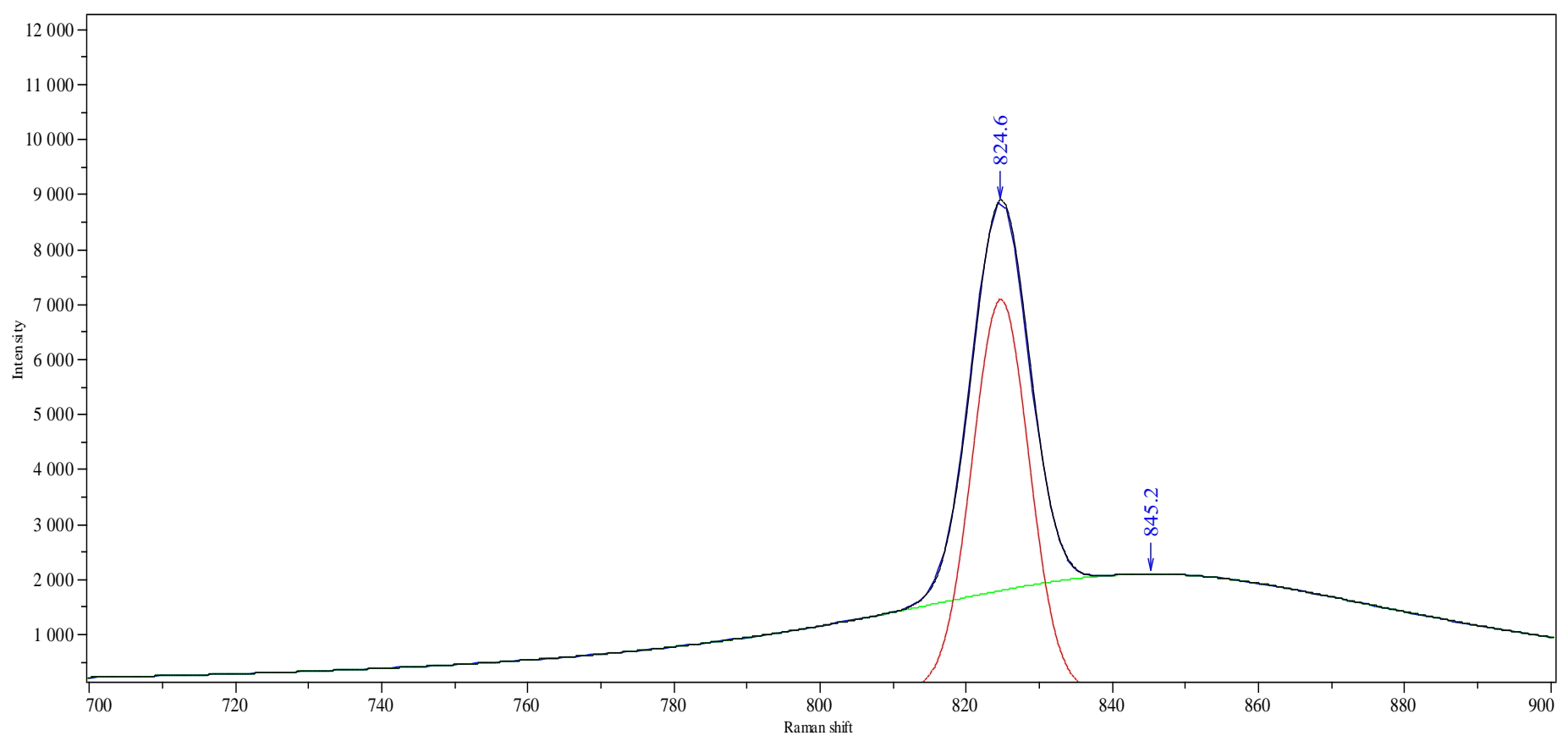

Figure 11 - b 

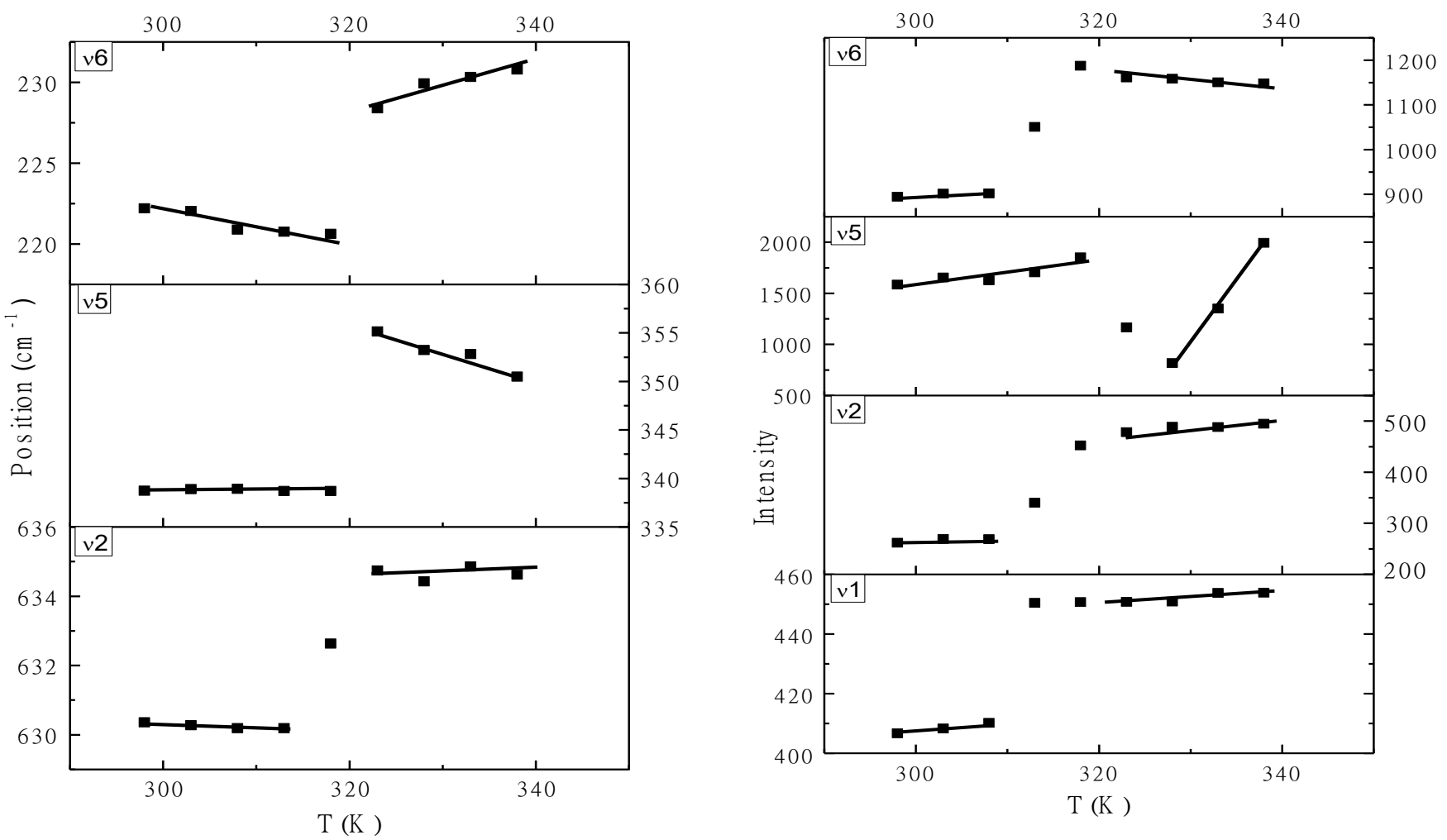

Figure 12-a

Figure 12 -b 

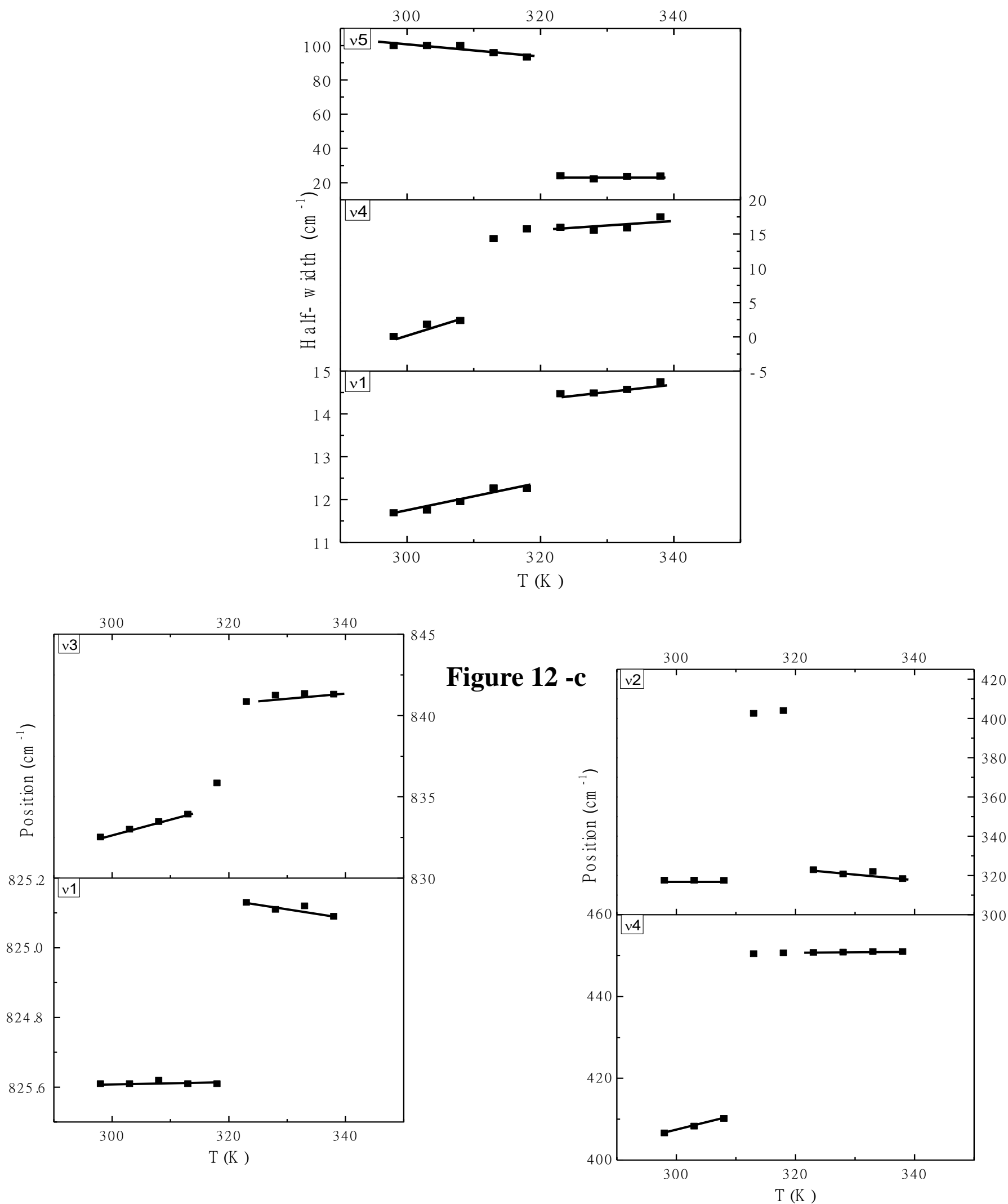


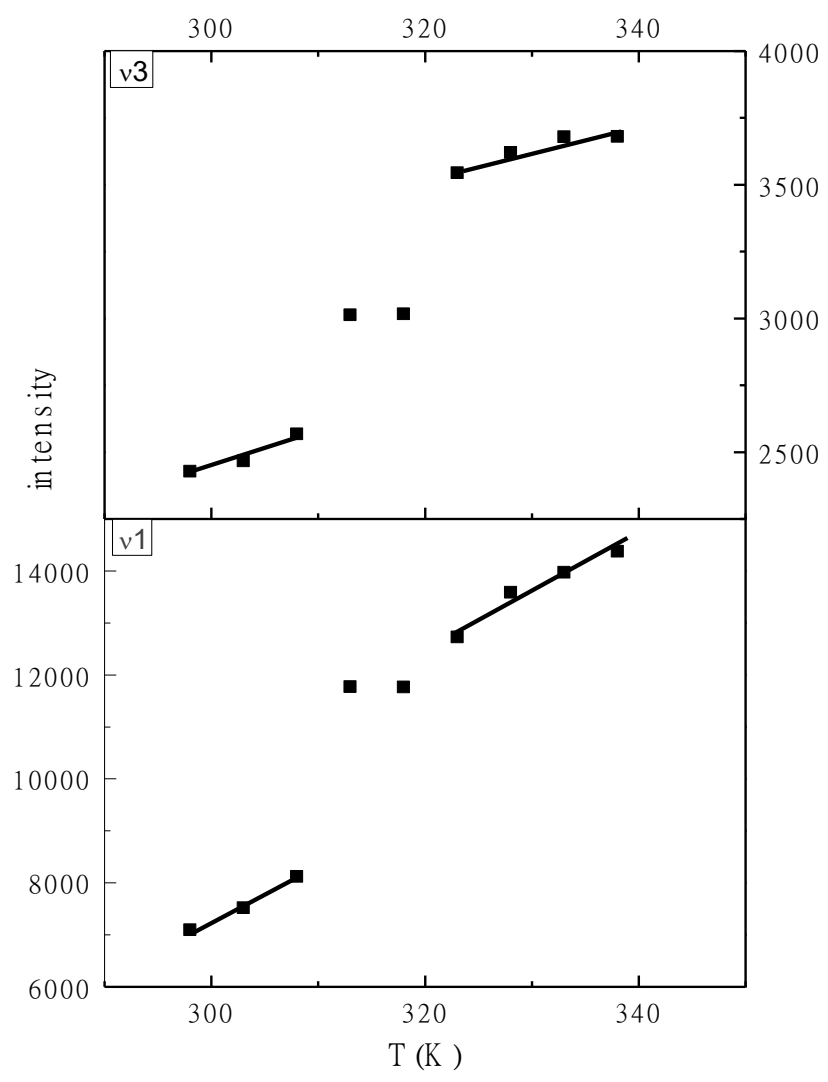

Figure 13- a

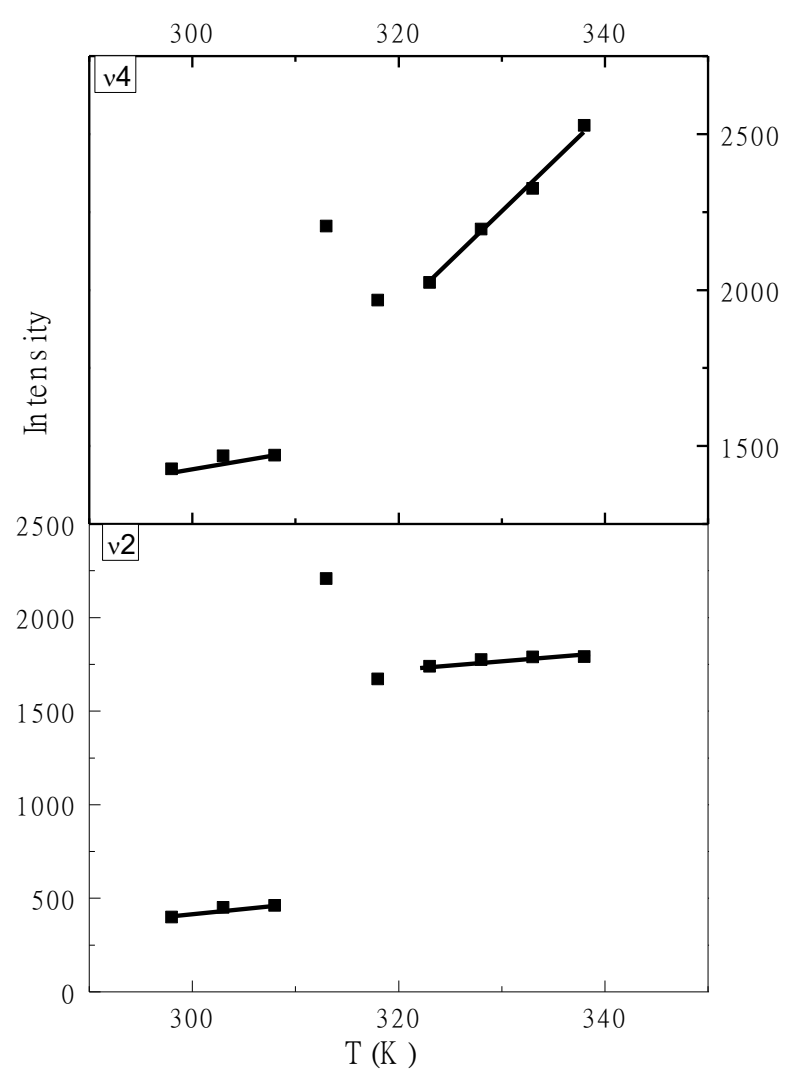

Figure 13- b 


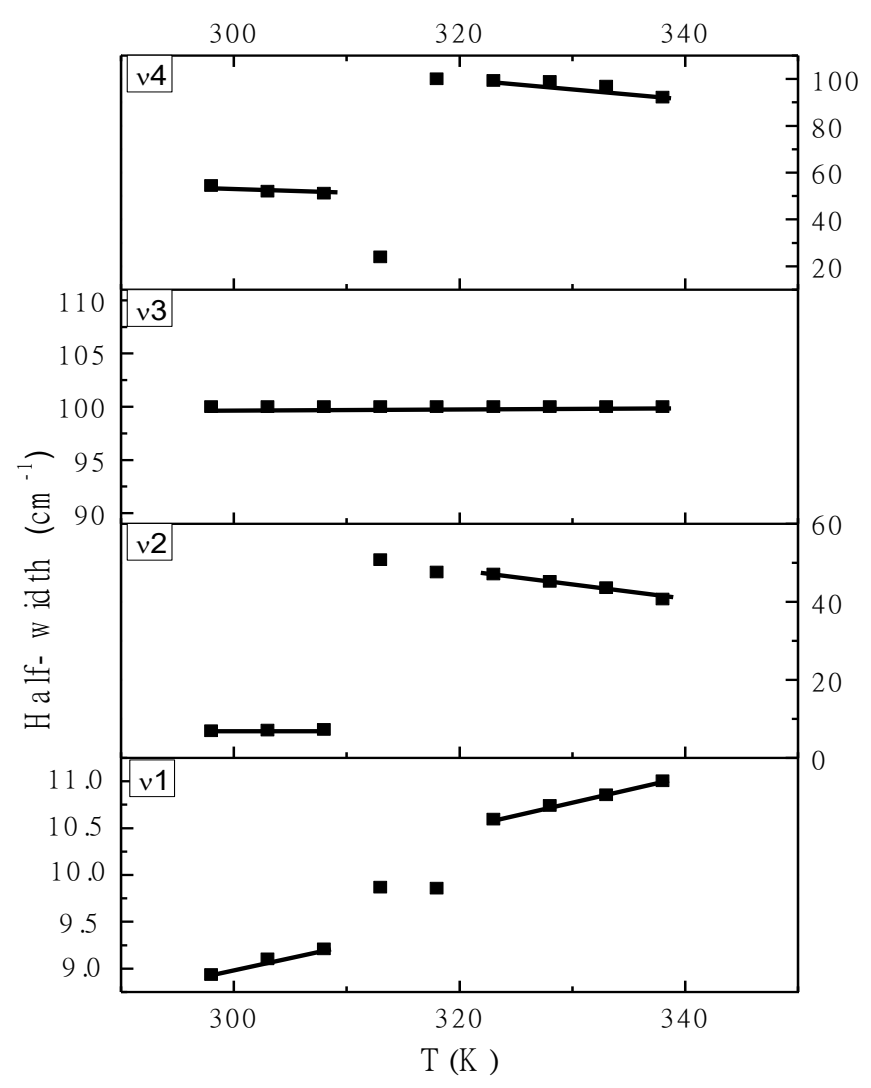

Figure 13-c 


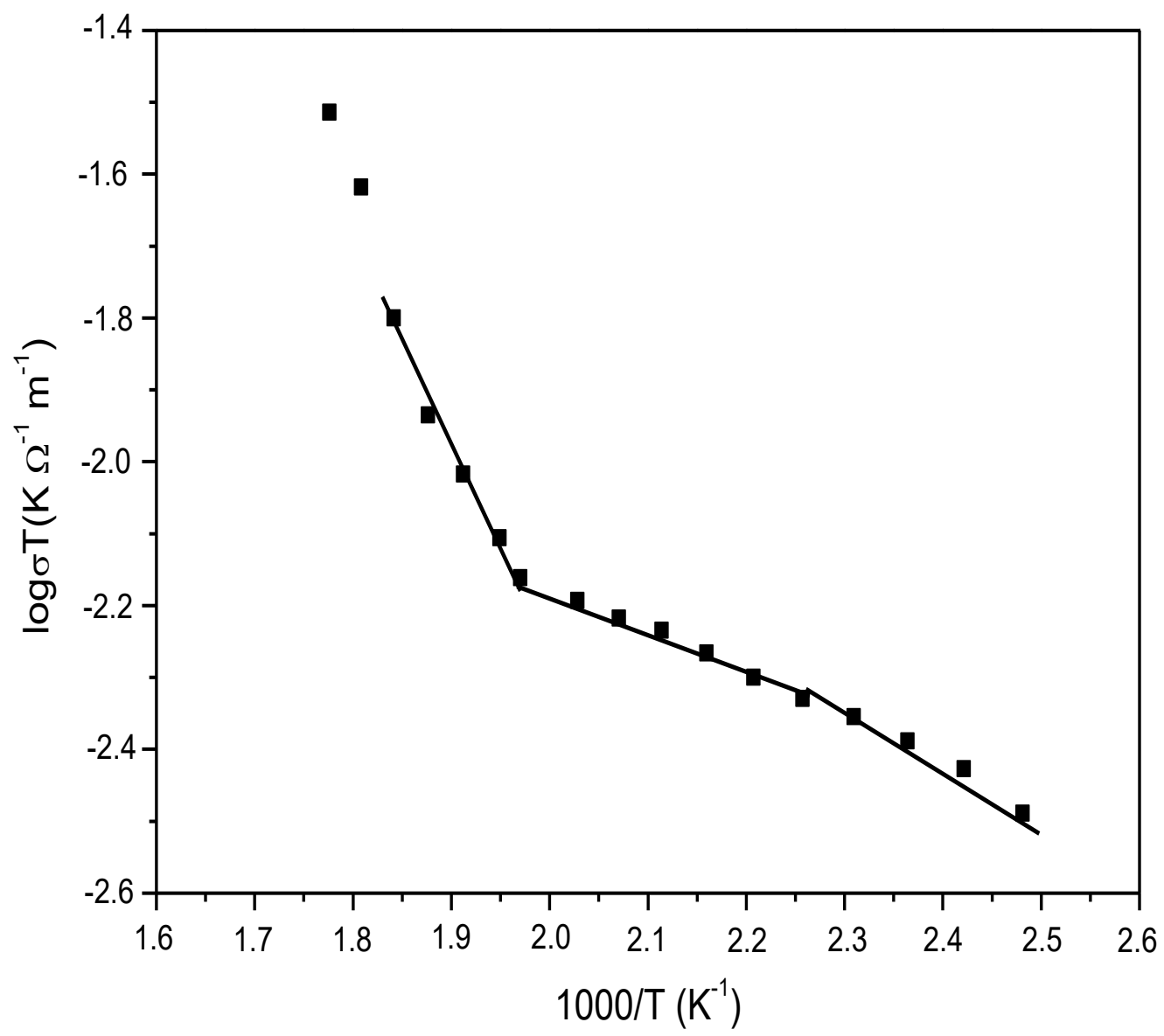

Figure 14 